Article

\title{
Investigation of Strategic Changes Using Patent Co-Inventor Network Analysis: The Case of Samsung Electronics
}

\author{
Sungchul Choi ${ }^{1}$ and Hyunseok Park ${ }^{2, *}$ \\ 1 Department of Industrial and Management Engineering, Gachon University, Seongnam-si, \\ Gyeonggi-do 13120, Korea; sc82.choi@gachon.ac.kr \\ 2 Department of Information System, Hanyang University, Seoul 04763, Korea \\ * Correspondence: hp@hanyang.ac.kr; Tel.: +82-2-2220-2396
}

Academic Editor: Marc Rosen

Received: 25 July 2016; Accepted: 8 December 2016; Published: 14 December 2016

\begin{abstract}
The aim of this paper is to propose a method to investigate a firm's strategic changes. Technologies or technological capabilities are a major resource for achieving competitive advantages, so a firm's R\&D effort to improve capabilities on specific technologies is aligned with strategic direction. Therefore, this research analyzes changes in R\&D efforts by identifying key R\&D personnel using patent co-inventor network and social network analysis. Based on characteristics of application and granted patents, the method analyzes current and future R\&D efforts and so identifies strategic changes of a firm. We conducted an empirical analysis using the patents of Samsung Electronics. Our method analyzed the current and future strategies of Samsung Electronics and the result shows clear strategic changes in their focal technologies and business.
\end{abstract}

Keywords: patent co-inventor analysis; technological capability; social network analysis

\section{Introduction}

In intense international competition and rapid technological change, companies have to build dynamic capabilities and continually adapt their corporate strategy to achieve sustainable competitive advantages. Since competitive advantage is achieved based on relative competitiveness, strategic changes of competitors are one essential input for a company to adjust its corporate strategy [1-3].

Technologies or technological capabilities are a critical resource for competitive advantage $[4,5]$. The success of many companies is derived from their outstanding technological capability [6]. Even though there are many ways to secure technological capability from inside and outside the company, internal R\&D is basically the most significant mechanism to gain technological capabilities. It is, therefore, logical that specific technological capabilities a company focuses its R\&D effort on are aligned with the strategic direction of the company and so changes of technological capabilities or R\&D efforts can explain strategic changes of a company, particularly with technology-oriented companies $[7,8]$.

Most previous research has tried to assess technological capabilities to identify signals of strategic changes of competitors and patents have been mainly used as a proxy data source [5,9-13]. However, objective measuring of changes of a company's technological capability level is difficult in that patent statistics-based quantitative approaches have high possibilities to provide inappropriate results in capability evaluation. For example, even though Samsung electrics has a large number of patents on user interface technology, its technological capabilities on user interface are not competitive (see our result in Section 4).

Therefore, this research tries to identify a firm's strategic changes from a different angle, i.e., changes in R\&D effort. R\&D effort-strategic resource allocation to R\&D projects to improve 
technological capabilities in specific technological domains-is directly aligned with strategic directions of a firm, because the goal of R\&D is basically to obtain technological capabilities for sustaining competitive advantage and companies never spend money on-or allocate their resources to-any business or technology that deviates from their strategic direction. From the resource-based view, intangible resources, mostly human resources, are a major determinant of a firm's decision for internal $R \& D$ and $R \& D$ human resources generally occupy the most important portion of R\&D expenditure $[6,9,14-19]$. Therefore, $R \& D$ human resource allocation can be a proxy variable to represent a firm's R\&D efforts on specific technological domains. In particular, key R\&D personnel, usually leaders of R\&D projects, can be directly aligned with strategic directions.

This paper proposes a method to investigate a firm's strategic changes using inventor information in patents. Specifically, the method analyzes the changes of a company's R\&D effort by identifying the key R\&D personnel in a patent co-inventor network using social network analysis (SNA) and their changes. In a patent co-inventor network, degree and betweenness centrality can analyze an inventor's research activeness and broadness, which are key factors to identify key R\&D personnel. We conducted an empirical analysis using the patents of Samsung Electronics. Samsung Electronics as one of the largest high-tech companies in the world had a clear strategic change in its major business from semiconductor devices to smart phones in early 2000s. Our method analyzed the current and future strategies of Samsung Electronics and the result shows the clear strategic changes in their R\&D and business.

This paper describes a literature review on the related search. We then provide a detailed description on the method and empirical analysis of Samsung Electronics case. Lastly, a conclusion will be drawn.

\section{Theoretical Background}

\subsection{Important RED Projects from a Human Resource Perspective}

Literatures have studied the relationship between $R \& D$ human resources and $R \& D$ projects. The following are the underlying characteristics for the proposed method.

First, an R\&D project conducted by relatively many researchers is usually an important project in the organization. Researchers are an important R\&D human resource in organizations [8] and allocation of researchers to $R \& D$ projects is directly influenced by the relative significance of the project. For this reason, an organization tends to allocate more resources to an important project than other projects. In a similar vein, Acedo et al. [20] showed that there is a high possibility that the more authors are involved, the more important the research generated is.

Second, a researcher involved in various R\&D projects has high possibility to be a core researcher having R\&D leadership. Hamel and Prahalad [21] asserted that capability is a vitally important factor for successful implementation of a strategy. In the view of R\&D perspective, if a specific R\&D project is strategically important, core researchers are firstly allocated to the project.

Finally, organizations usually provide a reward to researchers who have made a big contribution to important R\&D projects; monetary and positional incentive are general rewards in human resource management $[22,23]$. A successful researcher is more likely to get a higher position in the organization and may want to have a reputation in a research community. For example, Shuji Nakamura, who is an inventor of the Blue Light Emission Diode (LED), had moved from Nichia Corporation to University of California, Santa Barbara as a professor of engineering because of his major breakthrough in lighting technology.

\subsection{Patent Co-Inventor Network Analysis}

SNA techniques have been widely adopted as one of the prevailing patent analysis tools [24]. In patent bibliometric analysis, citation and co-inventor information, which represent knowledge flows and inventive relationships among inventors, are suitable for formulating a network. There are 
three major categories of studies using patent-based network analysis: technology transfer, research collaboration, and research performance Table 1.

Table 1. Related research using SNA techniques.

\begin{tabular}{ccc}
\hline Category & Description & Related Works \\
\hline Knowledge Transfer & $\begin{array}{c}\text { To analyze how technology knowledge of patents } \\
\text { transfers between R\&D groups, based on } \\
\text { a citation network with inventor information }\end{array}$ & $\begin{array}{c}\text { Han and Park [25], } \\
\text { Chao-Chih and Chun-Chieh [26] }\end{array}$ \\
\hline Research Collaboration & $\begin{array}{c}\text { To analyze how research groups are formulated } \\
\text { and collaborated by using a co-inventor network }\end{array}$ & $\begin{array}{c}\text { Cantner and Graf [27], } \\
\text { Vidgen et al. [28], } \\
\text { Lobo and Strumsky [29], } \\
\text { Sternitzke et al. [30], } \\
\text { Lei et al. [31] }\end{array}$ \\
\hline & $\begin{array}{c}\text { To analyze how important a patent is in an area } \\
\text { of technology by using citation-network analysis }\end{array}$ & $\begin{array}{c}\text { Chang et al. [32], } \\
\text { Wang et al. [33], }\end{array}$ \\
\hline
\end{tabular}

The first category is research for analyzing knowledge transfer. Research in this category describes how research groups or patent assignees refer other patents based on patent citation information. Han and Park [25] suggested an exploratory method for measuring inter-industrial knowledge flows by analyzing a citation network using United States Patent Class (USPC). The research discovered how much traditional industry technology affects emerging industry technology by analyzing co-citation degrees between related patents. Chao-Chih and Chun-Chieh [26] investigated knowledge diffusion between institutions and countries by analyzing patents related to Liquid Crystal Display (LCD). They identified key-players, knowledge spillover patterns, and overall knowledge spillover efficiency by analyzing SNA techniques and a patent citation network using assignee information.

The second category is about research analyzing how researchers (or inventors) collaborate by using co-inventor or co-assignee analysis. Cantner and Graf [27] analyzed a local inventor network of Jena, a German university town, by using SNA techniques. They tried to explain the job mobility of scientists and the technological overlap between assignees by means of network regression techniques. Lei, Zhao, Zhang, Chen, Huang, Zheng, Liu, Zhang, and Zhao [31] examined technological collaboration patterns in the solar cell industry by patent analysis using assignee and inventor information. This study categorized three different collaborative types such as same city, same country, and international collaboration, and analyzed how technological collaboration occurs between assignees or inventors.

The third category is about research analyzing research performance. Research in this category focuses on which patents are important in a patent network. Chang, Lai, and Chang [32] utilized a patent citation network analysis for finding basic patents and relationship between cited patents. This study tried to analyze groups of technology diffusion from basic patents by using the hierarchical cluster analysis. Wang, Chiang, and Lin [33] suggested a method to predict patent quality by analyzing brokerage or closure patents. In this research, they applied SNA techniques to analyze the network structure of patent citation and analyzed the relationship between forward patent citations and the brokerage and closure measures. They asserted that the quality of a patent is determined by the position in a citation network.

Even though the aforementioned studies are mainly studies conducted using patent data and SNA techniques, use of patent inventor information can provide a new chance to analyze different technological perspectives. Because inventor information of a patent document represents how much $R \& D$ human resources are allocated in a specific R\&D project, one can infer strategic directions of an R\&D organization by analyzing inventor information. In addition, SNA techniques can derive information on corporate strategies by considering technological context information with 
the inventors, such as technological fields from patent classification, invention date, and assignee's business domain. Moehrle, Walter, Geritz, and Müller [16] suggested a method for supporting human resource decision making in R\&D organization from the perspective of technological strategy. The research extracted researcher's technological profiles, technological knowledge, and their clusters by analyzing technological description in patents, and then they also analyzed technological context information, patent classification, and technological description of the classification, to complement the analysis results.

This paper proposes a method to investigate R\&D efforts of a firm based on patent co-inventor network analysis. To identify the R\&D effort and strategic direction, the proposed method utilizes SNA indicators, degree and centrality, and technological context information, such as IPC code, application date, and assignees' business environment information. As a result, the proposed method produces information on core inventors, the technology portfolio, and technological strategic intent of an R\&D organization.

\section{Method}

\subsection{Procedure}

The procedure for the proposed method consists of three steps:

(1) Collection of patent set;

(2) Analyzing patent co-inventor network;

(3) Analyzing key R\&D personnel.

First step is to collect the patent set for analysis. Since this research aims at analyzing specific organizations, a patent set can be easily identified by using the assignee name of the target organization and collected from the United States Patent and Trademark Office (USPTO) repository. To consider both current and future perspectives, patent applications and granted patents should be separately collected.

The second step is to analyze a patent co-inventor network. For this, a patent co-inventor network should be constructed. To extract node to node data set, $\left(\begin{array}{l}n \\ 2\end{array}\right)$ combinations are generated, where $n$ is a number of inventors in one patent document. For example, consider the inventor set of Inventors $=\left\{I_{1}, I_{2}, I_{3}\right\}$. The number of relationship among inventors are three which are from a Cartesian Product of set Inventors represented as Inventors $\times$ Inventors $=$ $\{(a, b) \mid a \in$ Inventors and $b \in$ Inventors, except $a=b\}$. In this case, each node $I_{i}$ has two relationships with other inventors and there is no direction between nodes. Using the extracted relationship data, a patent co-inventor network is generated using graph analysis tools, and this research utilizes $\mathrm{R}$, which is a computer language for statistics, and iGraph, which is a network analysis package for $\mathrm{R}[35,36]$. Key R\&D personnel of the target organization are identified based on inventor's research activeness and broadness which are measured by degree and betweenness centrality analysis; the details on the metrics will be described in Section 3.2.

The last step is to analyze the identified key R\&D personnel to relate them to corporate strategy. Basically, technological fields where the key R\&D personnel belong to or are focused can be identified by patent classification, e.g., international patent classification (IPC). Analysis of major IPCs of key R\&D personnel's patents can show their major technological fields and these technological fields are aligned with corporate strategy. In addition, contextual information from social network services, news, blogs, or a company's annual reports is helpful to verify the identified strategy. For example, information on the position or promotion of key R\&D personnel could be evidence to assure the result, because, in many cases, the leaders of major R\&D projects are appointed or promoted to high-level executive positions. 
All analysis procedure does not proceed at one time, but is looped. After the first analysis, the result should be compared to relevant contextual information and analyzed again to complement the first result. The analysis process is continuously repeated and completed though interactive analysis.

\subsection{Metrics}

The proposed method is aimed to analyze R\&D effort and its changes by analyzing a co-inventor network. Based on the focused capabilities, individual and organizational capability, and the targeted timeframe, current and future, this research can analyze four points of information on key R\&D personnel and technology portfolios (Figure 1).

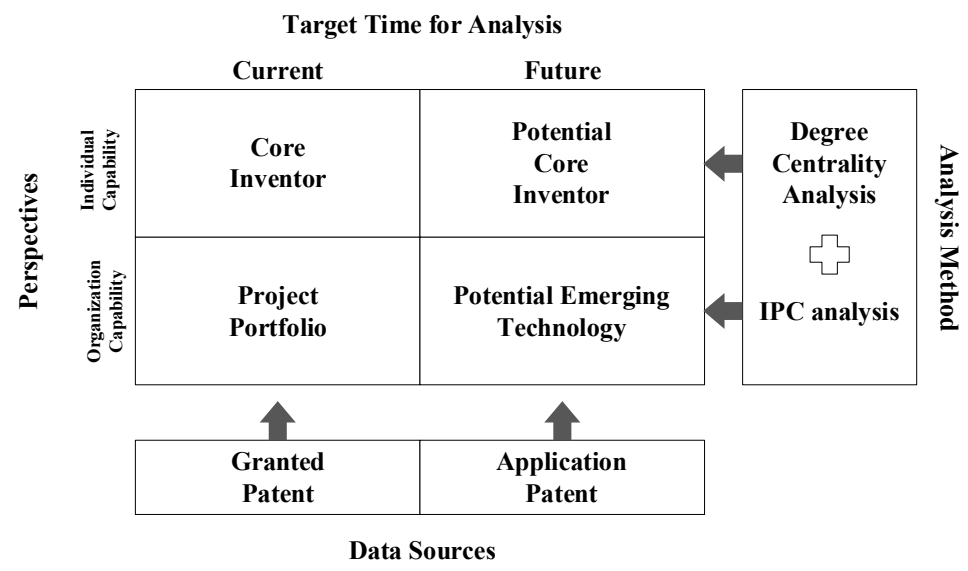

Figure 1. Framework for analysis.

For the analysis, two data sources and three methods are utilized. Patent data sources are divided into two types, patent application and granted patent. Patent application is a submitted patent which is just open to the public after a certain time regardless of legal right, whereas a granted patent is a publication patent which has the legal right of its claim. Generally, after 18 months from the filing date, patents are opened to the public as a patent application, and about one to two years later, patents are usually granted if it is qualified to be granted [37]. Therefore, granted patents can be the source for R\&D projects of the current important business domain of an R\&D organization, and patent applications are sources for preparing future important technology.

To identify key R\&D personnel, we utilize the degree and betweenness centrality analysis. In network theory, degree centrality indicates the number of links incident to a node [38]. The measure for degree centrality is defined as:

$$
\text { DEGREE }=d\left(n_{i}\right),
$$

where function $d$ is to calculate the number of other inventor-nodes that are connected to the focal inventor-node $n_{i}$ [39]. In SNA, degree can be used to represent the activity or influence of a specific node or actor in a network. An actor having a high degree can secure considerable reliability of information and is a highly influential actor in a network. Based on this concept, an inventor having a high degree centrality in co-inventor network can be interpreted as an active and core researcher in the organization.

The next indicator is betweenness centrality. The betweenness measures how a node is located between other nodes [40] and the normalized betweenness centrality can be calculated as:

$$
b_{i}=\sum_{j, k^{\wedge} i \neq j \neq k}^{n} \frac{g_{j i k}}{g_{j k}} / \frac{(n-1)(n-2)}{2}
$$

where function $n$ is the number nodes, $b_{i}$ is betwenness centrality of node $i, g_{j k}$ is the number of shortest paths from node $j$ to node $k$, and $g_{j i k}$ is the number of shortest paths from node $j$ to node $k$ that pass 
throughout node $i$. A node having high betweenness centrality is likely to be a broker or gate keeper of information in the network. The node can control the flow of information as an intermediate channel of information distribution. Generally, an actor which has high betweenness centrality in a network appears as a team leader of the network [41]. Based on this concept, betweenness centrality represents how various inventors are co-worked with a specific inventor in co-inventor network. Generally, high degree nodes have high betweenness centrality, however they are different. For example, if one node has 10 degrees with only one connecting node, another node has 10 degrees with nine connecting nodes, they have same degree value but the latter node has higher betweenness centrality value than the first one. That is to say, in a co-inventor network, an inventor who has high betweenness is likely to co-work with various inventors. The meanings of the indicators are summarized in Table 2.

Table 2. Degree and betweenness centrality of co-inventor network.

\begin{tabular}{ccl}
\hline \multicolumn{1}{c}{ Degree Type } & & \multicolumn{1}{c}{ Organizational Implications } \\
\hline High degree centrality & - & $\begin{array}{l}\text { To conduct research actively } \\
\text { To be likely to involve many R\&D projects }\end{array}$ \\
\hline High betwenness centrality & - & $\begin{array}{l}\text { To be likely to conduct R\&D projects with various other researchers } \\
\text { with active research } \\
\text { To be likely to be a leader of an R\&D project or R\&D group }\end{array}$ \\
\hline
\end{tabular}

\section{Empirical Analysis: Samsung Electronics}

\subsection{Data}

This research analyzes the patents of Samsung Electronics in the last five years. Samsung Electronics has rapidly grown up through clear strategic changes: from semiconductor devices to smart phones. Before the emergence of the smart phone market, the R\&D portfolio of Samsung Electronics heavily focused on developing semiconductor device related technologies. However, with the emergence of the smart phone market, Samsung Electronics' R\&D portfolio has been sharply diffused to smart phone related technologies. This research tries to empirically validate the strategic changes of Samsung Electronics through the proposed method.

The publication date of the patent set is from January 2010 to December 2014. In the case of granted patent, the application date is from January 2008 to December 2014, and in case of the patent applications, the application date is from January 2010 to December 2014. Because granted patents are a source for analyzing past $R \& D$ effort for current business and patent applications are a source for current R\&D effort for future business, the range of the period is different. Since it takes six years from the patent application to commercialization [42] and 1.5-2.5 years, on average, from application to granted patent [43] considering patent application for current strategy and granted patent for future strategy seems to be acceptable. In the case of Samsung Electronics, the granted patents include the technologies prior to smart phone technologies and applications include the technologies for post smart phone technologies.

In our patent set (Table 3), the total number of Samsung Electronics' patent applications are 19,877 and granted patents are 18,045. Although this research focuses only on Samsung Electronics' patents. The number of co-assignee patents are only 770 in grant and 1059 in patent applications, so this research added other co-assignee patents with Samsung Electronics. The total number of inventors are 11,975 and 13,348 for patents granted and applied for, respectively. The total number of IPCs are 4259 and 4826 for patents granted and applied for, respectively, excluding duplicated IPCs. Based on the patent data, the co-inventor networks are generated for grant and application. The grant co-inventor network has 11,975 nodes and 49,291 edges, and the application co-inventor network has 13,348 nodes and 56,693 edges. A node is an inventor and an edge is a co-inventing relationship between inventors. 
Table 3. Target data set for the case study of Samsung Electronics' patents in the last five years.

\begin{tabular}{cccccc}
\hline Publication Date & Type & Application Date & $\begin{array}{c}\text { Number of } \\
\text { Patents }\end{array}$ & $\begin{array}{c}\text { Number of } \\
\text { Inventors }\end{array}$ & $\begin{array}{c}\text { Number of } \\
\text { IPC Types }\end{array}$ \\
\hline January 2010 & Grant (B1, B2, S1) & January 2008 December 2014 & 18,045 & 11,975 & 4259 \\
December 2014 & Application (A1, A9) & January 2010 December 2014 & 19,877 & 13,348 & 4826 \\
\hline
\end{tabular}

\subsection{Analysis of Granted Patents}

This research formulates and analyzes co-inventor network of granted patents by extracting node-to-node data set, and iGraph package is utilized to calculate values of SNA indicators. The summary for results of co-inventor network analysis of granted patents is as shown in Table 4 . First, network density is 0.0002 which is very low. Because Samsung Electronics has collaborated with many other R\&D departments for several business units, such as mobile, home appliance, digital television, System LSI, and memory, with many inventors, they are not tightly connected between different business units. This is a common phenomenon of a bulky organization. Second, the mean value of the degree is 5.285 and its standard variation is 4.66. It means five inventors are co-worked for one patent on average and from 2 to 9 inventors generally are co-worked. Finally, the mean value of betweenness centrality is 24,590 and its standard variation is 101.505 . The value of standard variation shows relatively very higher than degree values. This means only a few inventors' betweenness centrality is extremely high and they are highly connected with other inventors.

Table 4. Summary for results of a co-inventor network analysis of granted patent.

\begin{tabular}{cccc}
\hline & Density & Degree & Betweenness Centrality \\
\hline Mean & 0.0002 & 5.285 & 24,950 \\
Standard Deviation & 4.66 & 101,505 \\
\hline
\end{tabular}

The top 20 IPC codes in granted patents of Samsung Electronics are shown in Table 5. In granted patent data, it appears that Samsung Electronics input researchers on R\&D projects related with semiconductor device technology in priority. Among top 20 IPC codes, 10 IPC codes are related with Memory, System LSI, and LED areas. The total number of researchers related to technology are 17,884. Outside of that, many researchers are allocated on the R\&D projects related with wireless systems and cellular phone business. Before the time of releasing a smart phone, Samsung Electronics had run a business for cellular phones with competing NOKIA which is a cellular phone company acquired by Microsoft.

The next analysis is for analyzing inventors who have a high degree and betweenness centrality. This research measures betweenness centrality of inventors and makes up a list of inventors having the highest betweenness centrality. Then, the current positions of the identified inventors were searched through a web search by using their name information. Because Samsung Electronics' high executive positions and recent promotions are open to the public, we can find an inventor name easily if an inventor is promoted to high executive positions. Also, the technological domains that the inventors are involved in are identified from the IPC codes of patent documents which are described by the inventors in Table 6.

From the analysis, one interesting fact is that the current positions of almost all inventors who have high betweenness centrality are executives in Samsung Electronics or eminent researchers of other departments. This means that if betweenness centrality is high, the possibility of having R\&D leadership is also high. Most inventors having high betweenness centrality was a leader of R\&D project or R\&D group in Samsung Electronics. The technological domains of the inventors are more related with semiconductor devices than smart phone devices. At that time, the main business of Samsung was a semiconductor device and semiconductor related technologies were more important than smart phone related technologies. However, the technologies related with cellular phones, not for 
smart phones, were actively researched, for example, wireless communication and image processing. In the case of analyzing granted patents, the results of IPC codes and individual inventor are almost same. At that time, Samsung Electronics had concentrated more on semiconductor devices than smart phone related technologies. Also, more inventors were allocated to developing semiconductor device related technologies.

Table 5. Top 20 IPC codes allocated to inventors in granted patents of Samsung Electronics.

\begin{tabular}{|c|c|c|c|}
\hline IPC & Number of Inventors & Technology for IPC & Business Area \\
\hline H04W4/00 & 4819 & Wireless channel access & Wireless Network Solution \\
\hline G06K9/00 & 2798 & User Interface related methods & Smart Phone \\
\hline G11C16/04 & 2736 & Read-only memories & \multirow{5}{*}{ Memory } \\
\hline H01L21/00 & 2725 & \multirow{2}{*}{$\begin{array}{l}\text { Manufacture or treatment of semiconductor } \\
\text { or solid state devices }\end{array}$} & \\
\hline H01L21/336 & 2507 & & \\
\hline H01L23/48 & 2316 & \multirow{2}{*}{ Semiconductor or other solid state } & \\
\hline H01L29/66 & 2024 & & \\
\hline G09G5/00 & 1769 & Circuits for visual indicators & TV Appliance \\
\hline H01L33/00 & 1756 & Semiconductor devices for light emission & LED \\
\hline H01L27/108 & 1691 & $\begin{array}{l}\text { A plurality of semiconductors } \\
\text { or other solid-state }\end{array}$ & Memory \\
\hline G06F15/16 & 1620 & Digital computers in general & Personal Computer \\
\hline $\mathrm{H} 04 \mathrm{~B} 7 / 00$ & 1525 & Radio transmission systems & Wireless Network Solution \\
\hline H04N7/12 & 1492 & Television systems & TV Appliance \\
\hline G06F13/00 & 1361 & Interconnection of circuit units & Memory System LSI \\
\hline H04W36/00 & 1337 & Handoff or reselecting arrangements & \multirow[b]{2}{*}{ Wireless Network Solution } \\
\hline H04W72/00 & 1334 & $\begin{array}{c}\text { Management of wireless resources } \\
\text { or wireless traffic }\end{array}$ & \\
\hline H01L29/78 & 1322 & Semiconductor devices & Memory \\
\hline H03M13/00 & 1293 & Electronics data decoding & Base technology \\
\hline H04L29/06 & 1217 & Circuits or systems & Base technology \\
\hline H01L21/8258 & 1202 & Semiconductor or solid state devices & Memory \\
\hline
\end{tabular}

Table 6. Inventors having highest betweenness centrality in granted patents of Samsung Electronics.

\begin{tabular}{ccccc}
\hline $\begin{array}{c}\text { Inventor Name } \\
\text { (Resource URL) }\end{array}$ & Degree & $\begin{array}{c}\text { Betweenness } \\
\text { Centrality }\end{array}$ & Current Position & Technology Area \\
\hline Jung-Hwan KIM & 52 & $2,517,903.782$ & N/A & $\begin{array}{c}\text { N/A (Because of name } \\
\text { ambiguity such as inventors } \\
\text { having same name, it is hard to } \\
\text { distinguish a specific inventor.) }\end{array}$ \\
\hline Ki-Hyun HWANG & 32 & $1,682,745.153$ & Vice President & Memory \\
\hline Sung Tae KIM & 36 & $1,314,883.601$ & Vice President & LED \\
\hline Kyoung Lae CHO & 37 & $1,303,646.368$ & N/A & Image Processing \\
\hline $\begin{array}{c}\text { Yun-Je OH } \\
\text { Bruno Clerckx }\end{array}$ & 58 & $1,284,607.899$ & Vice President & Wireless Communication \\
\hline $\begin{array}{c}\text { Sung Jin KIM } \\
\text { (http://goo.gl/jSVYlT) }\end{array}$ & 31 & $1,254,201.867$ & $\begin{array}{c}\text { Lecturer at Imperial } \\
\text { College }\end{array}$ & Communication (LTE) \\
\hline $\begin{array}{c}\text { Jae-Hee CHO } \\
\text { (http://goo.gl/WnzKZG) }\end{array}$ & 53 & $1,115,631.863$ & $\begin{array}{c}\text { Professor at Chonbuk } \\
\text { National University }\end{array}$ & Optoelectronics \\
\hline
\end{tabular}




\subsection{Analysis of Patent applications}

In case of patent applications, a co-inventor network is formulated based on the patents which are applied from 2010 to 2014 . Because of characteristics of patent applications, the patents are not fully open to the public and some of them are opened one or two years later. This might cause a situation that some values from the co-inventor network can be unstable. Because of this reason, as shown in Table 7, the mean values of the results are lower than the results of granted patents and the standard deviation values are extremely high. This is incomplete information and the summary results are not meaningful to analyze R\&D capabilities of an organization.

Table 7. The summary results of a co-inventor network of patent applications.

\begin{tabular}{cccc}
\hline & Density & Degree & Betweenness Centrality \\
\hline Mean & 0.000149143 & 4.649 & 17,393 \\
Standard Deviation & 12.86 & $8,618,822,950$ \\
\hline
\end{tabular}

The top 20 IPC codes of target patent applications are shown in Table 8. In contrast with granted patents, the major IPC codes are changed from semiconductor devices to electronic set products such as smart phones and TV appliances. In particular, many inventors are arranged for user interface related technology. This seems that Samsung Electronics prepared patent portfolios of user interface related technology after the Patent War with Apple (See Wikipedia (http:/ / en.wikipedia.org/wiki/ Apple_Inc._v._Samsung_Electronics_Co.)).

Table 8. Top 20 IPC codes allocated to inventors in patent applications of Samsung Electronics.

\begin{tabular}{cccc}
\hline \multicolumn{1}{c}{ IPC } & Number of Inventors & Technology for IPC & Business Area \\
\hline H04W72/04 & 3352 & Wireless channel access & Wireless Network Solution \\
\hline G06F3/041 & 2796 & & \\
G06F3/0488 & 2326 & User Interface related methods & Smart Phone \\
G06F3/01 & 2308 & & \\
G06F3/0481 & 2162 & & System LSI \\
G06F3/0484 & 2099 & System On Chips & Memory \\
\hline H04L29/06 & 2030 & Semiconductor devices & TV Appliance \\
\hline H01L29/78 & 1815 & Television systems & Memory \\
\hline H04N5/232 & 1802 & Semiconductor devices & Smart Phone Imaging \\
\hline H01L29/66 & 1626 & Imaging Unit & Device \\
\hline G09G5/00 & 1479 & Computing equipment & Set Products \\
\hline G06F17/30 & 1395 & System On Chips & System LSI \\
\hline G06F3/0482 & 1357 & User Interaction with computing equipment & Smart Phone TV Appliance \\
\hline H04L29/08 & 1353 & Secognizing patterns (i.e., characters) & Smart Phone \\
\hline G06K9/00 & 1251 & System On Chips & System LSI \\
\hline H04L5/00 & 1209 & Solid State Devices & Memory \\
\hline H01L21/02 & 1197 & Television systems & TV Appliance \\
\hline H04N13/00 & 1137 & Electronic Devices & Set Products \\
\hline H01F38/14 & 1109 & Batteries & Smart Phone \\
\hline H02J7/00 & 1104 & & \\
\hline
\end{tabular}

From the view of analyzing individual inventors, different with granted patents, it is hard to find information of inventors having a high degree and betweenness centrality in the Internet Tables 9 and 10). The reason is that patent applications was relatively recent research compared to granted 
patents and there was not enough time to get a reputation from research communities. Therefore, the inventors might not be rewarded yet and they might not be exposed to the public news. In contrast with granted patents, the most important characteristic of patent applications is that the inventors conducting research which is not the main business of Samsung Electronics have a high degree and betweenness centrality. For example, there are optics thin film, battery material, and carbon material which are material related technologies. Even though many inventors are arranged for user interface related $R \& D$ projects, there is no inventor related to the $R \& D$ project in the highest degree or betweenness centrality. Considering the characteristics of betweenness centrality value, it can be inferred that the size of $R \& D$ projects related to user interface are small, but there are many of the total number of inventors related with $R \& D$ projects. On the other hand, the number of patents related with material technology are relatively few, but the size of the R\&D projects is larger than user interface related R\&D projects. One interesting point is the inventor Jae-young CHOI who was the vice president of Samsung Advanced Institute of Technology (SAIT) having the highest degree in the co-inventor network of patent application, but a relatively low betweenness centrality. This means the $R \& D$ projects he joined are not conducted by major project teams, but very active with lots of patents. Considering that the topics of the R\&D projects are related with future technologies, such as carbon material, thermoelectric elements, and inorganic material, it can be inferred that Samsung Electronics has relatively small R\&D groups for preparing future technologies.

Table 9. The results of a co-inventor network of patent applications (Top five highest betweenness centrality).

\begin{tabular}{cccc}
\hline Inventor Name & Degree & Betweenness Centrality & Technology Area \\
\hline Sang Ho PARK & 25 & $2,558,598.32$ & $\begin{array}{c}\text { Optics Thin Film } \\
\text { (Laudry Machine) }\end{array}$ \\
\hline $\begin{array}{c}\text { Hyun-jin KIM } \\
\text { (http:/goo.gl/OXWSdU) }\end{array}$ & 31 & $2,355,259.44$ & Battery \\
\hline Sung-Ho CHOI & 19 & $2,005,281.401$ & Wireless Communication \\
\hline Do-Hyun KIM & 13 & $1,944,638.685$ & Optics Thin Film \\
\hline Eun-Hui BAE & 12 & $1,768,819.409$ & Wireless Communication \\
\hline
\end{tabular}

Table 10. The results of a co-inventor network of patent applications (Top five highest degree).

\begin{tabular}{cccc}
\hline Inventor Name & Degree & Betweenness Centrality & Technology Area \\
\hline Jae-young CHOI & 53 & $1,115,306$ & $\begin{array}{c}\text { Carbon material, thermoelectric } \\
\text { elements, inorganic material }\end{array}$ \\
\hline $\begin{array}{c}\text { Chang-soo LEE } \\
\text { (http://goo.gl/OXWSdU) }\end{array}$ & 33 & $455,627.5$ & Transferring data \\
\hline Hyeong-sik CHO & 33 & $564,297.8$ & $\begin{array}{c}\text { Fibre optic devices, structural } \\
\text { combinations of lighting devices }\end{array}$ \\
\hline $\begin{array}{c}\text { Boon Loong Ng } \\
\text { (http://goo.gl/se4A7F) }\end{array}$ & 31 & $115,543.2$ & LTE, LTE-Advanced \\
\hline Chi-Woo LIM & 31 & 593,338 & Wireless communication \\
\hline
\end{tabular}

\subsection{Discussion}

From the empirical analysis of the Samsung Electronics case, we extracted the following implications:

- In the case of granted patents, the results show the tendency that if inventors have a high betweenness centrality, they have a high R\&D leadership. Because betweenness centrality is high when the inventor is linked to many other inventors, there is a high possibility that the inventor is at the center of the R\&D projects and the leader of the R\&D group. This kind of inventor has 
a high potential to be promoted to an executive in the organization or to move to another $R \& D$ department as a core researcher.

- In the case of patent applications, the proposed method helps to find organization R\&D effort with the hidden information which is not extracted for IPC codes. Considering the number of inventors arranged on each IPC code, Samsung Electronics have allocated many researchers to R\&D projects related to user interface technologies to construct the patent portfolio for preparing patent suit against Apple. However, it appears that the inventors related to material technology have a relatively high degree and betweenness centrality. This means that Samsung Electronics' strategy to build a patent portfolio for user interface is just to apply for many patents with many small-sized R\&D teams, on the other hand, they prepare core capabilities related to material technology with a few big-sized R\&D teams for supporting current business or preparing emerging business.

- Finally, the preparation for future direction is also captured by the proposed method. In an analysis of patent applications, the inventor who has high degree but relatively low betweenness centrality is identified. He works for emerging technologies related to carbon material, inorganic material, and thermoelectric element. This fact shows that Samsung Electronics has constructed small size, but active R\&D teams for preparing future technology and has crafted various patent portfolios. We think these are the strategic directions of Samsung Electronics.

\section{Conclusions}

This research proposes a method to investigate the strategic changes of a company by analyzing inventor information in patent documents and technological context information. The proposed method helps to understand the core inventors, R\&D portfolio, and hidden R\&D strategies using patent co-inventor network and SNA technique. In addition, this research conducted the case study of Samsung Electronics' R\&D organization and identified strategic changes of them.

The main contribution of this research can be divided into two parts: empirical and methodological perspectives. From an empirical perspective, this research can identify a firm's strategic changes, which are difficult to identify by measuring technological capabilities. Therefore, the method can help understand strategic changes of competitors. About the methodological contribution, this research uses inventor information as an input for analyzing R\&D effort and strategic changes of a firm. Considering that most existing patent analysis-based research methods using inventor information or SNA techniques have focused on knowledge transfer or research collaboration, this research is a meaningful attempt to link patent inventor information to strategic changes.

To improve the proposed method, some issues must be resolved in the future. First, the name ambiguity problem should be solved for more efficient analysis. In a patent document, sometimes, inventor's names are the same for different people or written wrongly by human error. This can generate inappropriate results. For example, if two inventors having same name and relatively high betweenness centralities are considered as one inventor, this inventor will be overestimated. To resolve this problem, the method for distinguishing inventor names should be developed by using a data mining approach such as an association rule with IPC codes or co-inventor information. Second, the scope of case study needs to be extended. Even though this research only analyzed the Samsung Electronics case, other IT companies, including Apple, Nokia, Blackberry, and Huwei, would be good to analyze by the proposed method to verify the applicability and reliability.

Acknowledgments: This research was supported by Basic Science Research Program through the National Research Foundation of Korea(NRF) funded by the Ministry of Education(NRF-2015R1C1A1A01056185), and by the Gachon University research fund of 2014 (GCU-2014-0108).

Author Contributions: Sungchul Choi and Hyunseok Park designed the framework and experiments, Sungchul Choi performed the experiments, Sungchul Choi and Hyunseok Park wrote the manuscript.

Conflicts of Interest: The authors declare no conflict of interest. 


\section{References}

1. Barney, J. Firm resources and sustained competitive advantage. J. Manag. 1991, 17, 99-120.

2. Andrews, K.R.; David, D.K. The Concept of Corporate Strategy; Richard D Irwin: New York, NY, USA, 1987.

3. Wernerfelt, B. A resource-based view of the firm. Strateg. Manag. J. 1984, 5, 171-180.

4. Bohn, R.E. Measuring and managing technological knowledge. Sloan Manag. Rev. 1994, 36, 61.

5. Ernst, H. Patent information for strategic technology management. World Pat. Inf. 2003, 25, $233-242$. [CrossRef]

6. Del Canto, J.G.; Gonzalez, I.S. A resource-based analysis of the factors determining a firm's R\&D activities. Res. Policy 1999, 28, 891-905.

7. Roussel, P.A.; Saad, K.N.; Erickson, T.J. Third Generation RED: Managing the Link to Corporate Strategy; Harvard Business Press: Brighton, MA, USA, 1991.

8. Allen, T.J.; Katz, R. Age, education and the technical ladder. IEEE Trans. Eng. Manag. 1992, 39, $237-245$. [CrossRef]

9. Jung, S.; Imm, K.-Y. The patent activities of Korea and Taiwan: A comparative case study of patent statistics. World Pat. Inf. 2002, 24, 303-311. [CrossRef]

10. Schoenecker, T.; Swanson, L. Indicators of firm technological capability: Validity and performance implications. IEEE Trans. Eng. Manag. 2002, 49, 36-44. [CrossRef]

11. Chakrabarti, A.K. Competition in high technology: Analysis of patents of US, Japan, UK, France, West Germany, and Canada. IEEE Trans. Eng. Manag. 1991, 38, 78-84. [CrossRef]

12. Park, H.; Yoon, J.; Kim, K. Identification and evaluation of corporations for merger and acquisition strategies using patent information and text mining. Scientometrics 2013, 97, 883-909. [CrossRef]

13. Scherer, F.M. The propensity to patent. Int. J. Ind. Organ. 1983, 1, 107-128. [CrossRef]

14. Armstrong, M. A Handbook of Human Resource Management Practice; Kogan Page: London, UK, 2001.

15. Price, A. Human Resource Management in a Business Context; Cengage Learning EMEA: London, UK, 2004.

16. Moehrle, M.G.; Walter, L.; Geritz, A.; Müller, S. Patent-based inventor profiles as a basis for human resource decisions in research and development. RED Manag. 2005, 35, 513-524.

17. Kim, Y.; Cha, J. Career orientations of R\&D professionals in korea. RED Manag. 2000, 30, 121-138.

18. Hendriks, M.; Voeten, B.; Kroep, L. Human resource allocation in a multi-project R\&D environment: Resource capacity allocation and project portfolio planning in practice. Int. J. Proj. Manag. 1999, 17, 181-188.

19. Huemann, M.; Keegan, A.; Turner, J.R. Human resource management in the project-oriented company: A review. Int. J. Proj. Manag. 2007, 25, 315-323. [CrossRef]

20. Acedo, F.J.; Barroso, C.; Casanueva, C.; Galán, J.L. Co-authorship in management and organizational studies: An empirical and network analysis. J. Manag. Stud. 2006, 43, 957-983. [CrossRef]

21. Hamel, G.; Prahalad, C.K. Strategic Intent; Harvard Business School Publishing Corporation: Boston, MA, USA, 2005; Volume 83, p. 14.

22. Legge, K. What is human resource management? In Human Resource Management; Springer: Berlin, Germany, 1995; pp. 62-95.

23. Storey, J. Human Resource Management: A Critical Text; Cengage Learning EMEA: London, UK, 2007.

24. Argyres, N.S.; Silverman, B.S. R\&D, organization structure, and the development of corporate technological knowledge. Strateg. Manag. J. 2004, 25, 929-958.

25. Han, Y.-J.; Park, Y. Patent network analysis of inter-industrial knowledge flows: The case of korea between traditional and emerging industries. World Pat. Inf. 2006, 28, 235-247. [CrossRef]

26. Chao-Chih, H.; Chun-Chieh, W. The use of social network analysis in knowledge diffusion research from patent data. In Proceedings of the International Conference on Advances in Social Network Analysis and Mining (ASONAM '09), Athens, Greece, 20-22 July 2009; pp. 393-398.

27. Cantner, U.; Graf, H. The network of innovators in Jena: An application of social network analysis. Res. Policy 2006, 35, 463-480. [CrossRef]

28. Vidgen, R.; Henneberg, S.; Naudé, P. What sort of community is the European Conference on Information Systems? A social network analysis 1993-2005. Eur. J. Inf. Syst. 2007, 16, 5-19. [CrossRef]

29. Lobo, J.; Strumsky, D. Metropolitan patenting, inventor agglomeration and social networks: A tale of two effects. J. Urban Econ. 2008, 63, 871-884. [CrossRef] 
30. Sternitzke, C.; Bartkowski, A.; Schramm, R. Visualizing patent statistics by means of social network analysis tools. World Pat. Inf. 2008, 30, 115-131. [CrossRef]

31. Lei, X.-P.; Zhao, Z.-Y.; Zhang, X.; Chen, D.-Z.; Huang, M.-H.; Zheng, J.; Liu, R.-S.; Zhang, J.; Zhao, Y.-H. Technological collaboration patterns in solar cell industry based on patent inventors and assignees analysis. Scientometrics 2013, 96, 427-441. [CrossRef]

32. Chang, S.-B.; Lai, K.-K.; Chang, S.-M. Exploring technology diffusion and classification of business methods: Using the patent citation network. Technol. Forecast. Soc. Chang. 2009, 76, 107-117. [CrossRef]

33. Wang, J.-C.; Chiang, C.-H.; Lin, S.-W. Network structure of innovation: Can brokerage or closure predict patent quality? Scientometrics 2010, 84, 735-748. [CrossRef]

34. Abbasi, A.; Altmann, J. On the correlation between research performance and social network analysis measures applied to research collaboration networks. In Proceedings of the 44th Hawaii International Conference on System Sciences (HICSS), Kauai, HI, USA, 4-7 January 2011.

35. Csardi, G.; Nepusz, T. The igraph software package for complex network research. Int. J. Complex Syst. 2006, 1695, 1-9.

36. R Core Development Team. R: A Language and Environment for Statistical Computing, The R Foundation for Statistical Computing: Vienna, Austria, 2011.

37. Popp, D.; Juhl, T.; Johnson, D.K. Time in purgatory: Examining the grant lag for us patent applications. Top. Econ. Anal. Policy 2004, 4, 1-45. [CrossRef]

38. Diestel, R. Graph Theory; Springer: Berlin, Germany, 2005.

39. Carrington, P.J. Models and Methods in Social Network Analysis; Cambridge University Press: Cambridge, UK, 2005.

40. Freeman, L.C. Centrality in social networks conceptual clarification. Soc. Netw. 1978, 1, 215-239. [CrossRef]

41. Freeman, L.C.; Roeder, D.; Mulholland, R.R. Centrality in social networks: II. Experimental results. Soc. Netw. 1979, 2, 119-141. [CrossRef]

42. Napolitano, G.; Sirilli, G. The patent system and the exploitation of inventions: Results of a statistical survey conducted in Italy. Technovation 1990, 10, 5-16. [CrossRef]

43. Hall, B.H.; Jaffe, A.B.; Trajtenberg, M. The NBER Patent Citation Data File: Lessons, Insights and Methodological Tools; National Bureau of Economic Research: Cambridge, MA, USA, 2001.

(C) 2016 by the authors; licensee MDPI, Basel, Switzerland. This article is an open access article distributed under the terms and conditions of the Creative Commons Attribution (CC-BY) license (http://creativecommons.org/licenses/by/4.0/). 